EISSN: $2706-7947$ ISSN: 2077- 4613

DOI: $10.36632 / \mathrm{mejas} / 2021.11 .3 .48$

Journal homepage: www.curresweb.com

Pages: 603-611

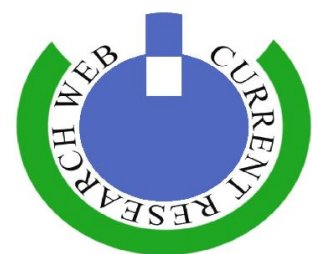

\title{
Synthesis of Silver Nanoparticles Using Low-Grade Date Syrup for Production of Active Edible Films
}

\author{
Sanaa R.A. Rohaiem, Abeir M.F. Elbaz and ElKady A. A. \\ Food Engineering and Packaging Dept., Food Tech. Res. Institute, Agric. Res. Center, Giza, Egypt \\ Received: 05 June $2021 \quad$ Accepted: 04 July $2021 \quad$ Published: 10 July 2021
}

\begin{abstract}
Nowadays more researchers are giving more attention toward eco-friendly biosynthesis of green silver nanoparticles. In this study, the possible role of bioactive compounds date syrup extract in reducing silver nitrate into silver nanoparticles is highlighted. These biosynthesized nanoparticles were characterized with the help of UV-visible spectrophotometer, atomic absorption spectroscopy and FTIR spectroscopy. It was observed that date extract can reduce silver ions into silver nanoparticles within 26 min. of reaction time. The intense peaks centered near $420 \mathrm{~nm}$ by UV-analysis, affirmed the reduction of $\mathrm{Ag}^{+}$to $\mathrm{Ag}^{0}$. ASS analysis showed decrease in concentration of $\mathrm{Ag}^{+}$ions from $5.6 \mathrm{ppm}$ to 0.04 ppm with 26 min. FTIR measurements confirms the presence of $\mathrm{CH}_{3}$ and $\mathrm{CH}_{2}$ stretching, $\mathrm{C}=\mathrm{O}$ carbonyl group, $\mathrm{C}-\mathrm{S}$ stretch and $\mathrm{OH}$ stretching in the analysis which exist in bioactive compounds of date syrup extract, such as phenols, all act as reducing and stabilizing agents for silver nanoparticles and protect it from further changes. Antibacterial activity of these synthesized nanoparticles was studied against gram positive and negative pathogenic bacteria. Additionally, an edible films of pectin reinforced with AgNPs were prepared to evaluate its antibacterial efficiency to be used as food packaging materials. The findings suggest that antibacterial activity of biosynthesized AgNPs from date fruit shows a promising zone of inhibition pathogenic bacteria. Also, results exhibited clear bacteriostatic activity of pactin/AgNPs blend films against all microbes tested after 5 weeks of storage a meat patty samples at $4^{\circ} \mathrm{C}$ and its decreasing diminution reached to about eight-fold the decreasing of control sample.
\end{abstract}

Keywords: Silver nanoparticles, Date extract, Biosynthesis, Antibacterial Activity.

\section{Introduction}

Phoenix dactylifera is the scientific name of date tree, a member of Palmaceae family. Date fruits are rich in antioxidants in peels and / or in fruits including: phenols, tannins, flavones, alkaloids, glycosides, saponins, resins and vitamins such as $\mathrm{A}, \mathrm{C}, \mathrm{H}, \mathrm{B}_{1}, \mathrm{~B}_{2}, \mathrm{~B}_{3}$ and $\mathrm{B}_{6}$. Many bioactive compounds were found in date syrup such as Camphene acid, Veriolic acid, Dactileviric acid, Chlorogenic acid, Trans Cinamic acid, Comaric acid, Caphiol, Campherol, Myristin, Cirastin, Chatshin, 1, 3 - beta diglocan, Epiganic and Liotolwin. (Reem et al., 2017)

One hundred grams of dried date syrup contains: 277 calories, 75 gm carbohydrates, $7.0 \mathrm{gm}$ fibers, 2.0 gm proteins, $1.74-2.67 \mathrm{mg}$ simple polyphenols, $85-100 \mathrm{mg}$ soluble tanins, $12.6-39.2 \mathrm{mg}$ insoluble tannins, $80-100 \mathrm{IU}$ vitamin A, $0.07 \mathrm{mg} \mathrm{B}_{1}, 0.03 \mathrm{mg} \mathrm{B}_{2}, 2.2-3.0 \mathrm{mg} \mathrm{B}_{3}$ (Niacin), $0.8-3.0$ $\mathrm{mg}$ vitamin $\mathrm{C}$, and $2-3 \mathrm{mg}$ Caviol. (Keiper, 2020)

Also date fruits contains some necessary minerals which act as antioxidants such as Selenium. Selenium have been recognized to have antioxidant potential and has been described to exceed antioxidant compounds to animal protein. (One gm of dried date syrup contains $1.47-2.97$ microgram selenium). These minerals can save the daily human consumption need by $20 \%$ of potassium, $14 \%$ of magnesium, $18 \%$ of cupper, $15 \%$ of manganise and 5\% of iron (Sahoo et al., 2019).

In the past, antioxidant agents from plant was established an amazing consideration due to their talent to protect food stuffs and avoid rancidity caused by oxidation (Fatma et al., 2018). 
Recently, researchers are now focusing on use of plants for green synthesis of nanoparticles which they are finding that metal nanoparticles synthesized from plants have all kind of unexpected benefits, as they are free from toxic chemicals, easy handling, lower cost, social acceptance, develop environmental friendly methods (Jeyashree and Revathi, 2017).

It is believed that metal nanoparticles kill bacteria by one of the following mechanisms: (i) interference with vital cellular processes by binding to sulfhydryl or disulfide functional group on the surfaces of membrane proteins and interfering with enzymes, (ii) disruption of DNA replication, (iii) oxidative stress through the catalysis of reactive oxygen species (Ducan, 2011).

Specific methodologies have been used to synthesize noble metal nanoparticles of particular size and shape, this allows nanomaterials to be able to attach more copies of biological molecules, which confers greater efficiency due to materials in the nanoscale have a higher surface - to - volume ratio when compared with their microscale counterparts (Neethirajan and Jayas, 2011).

Silver nanoparticles can be synthesized using various approaches including chemical, physical and biological routs. Although chemical methods of synthesis requires short period of time for synthesis of large quantity of nanoparticles, still this method has a disadvantage that is also requires capping agents for size stabilization of the nanoparticles (Supraja et al., 2013). Thus there is an increasing demand for green nanothechnology for synthesis of stable nanoparticles.

Synthesis of nanoparticle by biological method is through microbes like Aspergillus flavus (Vigneshwaran et al., 2007), Pseudomanas spp. (Silambarasan and Jayanthi, 2013) and plant sources such as chenopodium album (Dwivedi and Gopal, 2010), Acalypha indica (Krishnaraj et al., 2010), Cynodon dactyion (Supraja et al., 2013). Glycyrrhiza glabra (Dinesh et al., 2012), Nigella sativa etc.

Although, microorganisms have already been reported as efficient bio-reducing agent for metal nanoparticles, but it increases the issues related to elaborate microbial culture handling used in microbe mediated biosynthesis of metal nanoparticles (Bukar et al., 2018).

Therefore, plants and spices provide a better platform for nanoparticles synthesis, which plant phytochemical with antioxidant of reducing properties are usually responsible for reduction of metal compounds into their respective nanoparticles (Balaprasad et al., 2005).

Today, manufacturers add silver nanoparticles to hundreds of consumer products, including food storage containers, clothing, computer key boards, cosmetics, pillows, cellphones and medical appliances. The properties of these consumables can be further improvised by using silver nanoparticles synthesized via the ecofriendly green routes.

Active packaging is an innovative concept in which the package, the product, and the environment interact to prolong the shelf-life, enhance safety, or improve sensory properties, while maintaining the stability and quality of the product (Khalil et al., 2013; Anngkana et al., 2016).

This concept, which is of special importance in the area of fresh and extended shelf life foods, has benefited recently by the use of nanotechnology materials including nanocoatings and nanoparticles (Grazlela et al., 2017).

Among different plants, the seeds of some spices had shown to exhibit various medicinal properties such as antioxidant, antibacterial and anticancer activity (Bourgou et al., 2012). But till date, up to our knowledge, there is no report on synthesis of silver nanoparticles from the syrum of rich antioxidant fruits. Hence, the present study was deliberately aimed with a simple and an effective approach of synthesizing silver nanoparticles using the syrup of date fruit as a reducing agent and to treat against spoilage and diseases causing bacteria.

The present study focused on (i) The use of low grade date syrup as a template for silver nanoparticles synthesis and to exploit their medicinal importance in terms of antimicrobial activity. (ii) To prepare pectin / AgNPs blend films and to characterize their properties for their potential use as food packaging application.

\section{Materials and Methods}

\subsection{Materials}

All of reagent and ultrapure water used throughout the experiments were purchased from SigmaAldrish (St. Louis, Mo, USA). Date fruits were purchased from a local market (Giza, Egypt). 


\subsubsection{Bacterial Strains}

Three bacterial strains used in the study included E. Coli 0157:H7 (ATCC 43895), S. aureus (ATCC 11988) and B. subtilis (ATCC 64540) were obtained by food Sci. Dep. Agric. Collage, Mansoura Univ., Egypt.

\subsection{Methods}

\subsubsection{Preparation of date syrup}

The syrup used for the synthesis of silver nanoparticles was prepared by taking $750 \mathrm{gm}$ of thoroughly washed destoned fresh low grade date, and extract the syrup by soaking at a suitable time in hot water at $65^{\circ} \mathrm{C}$. The suspension was homogenized by blending for $5 \mathrm{~min}$. at high speed, and the homogenized suspension was centrifuged (to separate the date extract from the fibers and insoluble matters), the supernatant fraction was filtrated through whatman No.1 and evaporated by vacuum evaporator $\left(45^{\circ} \mathrm{C}\right)$ and made up to a concentration of $70^{\circ}$ Brix and stored at $4^{\circ} \mathrm{C}$ for further use in plastic bag.

\subsubsection{Preparation of $\mathrm{AgNO}_{3}$ solutions}

A weight of $3.34 \mathrm{mg}$ of $\mathrm{AgNO}_{3}$ salt was suspended in $30 \mathrm{ml}$ of distilled water, to obtain $1 \mathrm{mM}$ of $\mathrm{AgNO}_{3}$, and then three another aqueous $\mathrm{AgNO}_{3}$ solutions with different standard concentration (2 $\mathrm{mM}, 3 \mathrm{mM}$, and $4 \mathrm{mM}$ ) were prepared.

\subsubsection{Optimization and synthesis of silver nanoparticles}

Each $10 \mathrm{ml}$ of the prepared date extract was taken in separate conical flask. $50 \mathrm{ml}$ of each above $\mathrm{AgNO}_{3}$ solutions was added to the respective flasks drop by drop with continuous stirring for bioreduction process of the $\mathrm{Ag}^{+}$ions at room temperature under dark conditions. The conical flasks were sealed using cotton plugs and observed for color change. The color of the reaction mixture changes to dark brown color indicating the reaction of $\mathrm{Ag}^{+}$ions to AgNPs. Finally, the solution mixture was centrifuged at $5000 \mathrm{rpm}$ for $20 \mathrm{~min}$. and the resulting substrate was collected and the pellet formed was dissolved in $0.1 \mathrm{ml}$ of toluene water and oven dried at $65^{\circ} \mathrm{C}$ for $20 \mathrm{~min}$. (to avoid clumping of particles (Prathna et al., 2011).

\subsubsection{Characterization of silver nanoparticles-UV-Vis spectroscopy:}

The formation and the stability of metal nanoparticle in aqueous solution are monitored by UVViS Spectroscopy. The spectrum was taken for the reaction mixture immediately when it is prepared. The bio-reduction of precursor silver ions was detected and confirmed by sampling of aliquots $(1 \mathrm{ml})$ at different time intervals. Absorption measurements were carried out on UV-visible spectrophotometer (ELICO U.V. 165) at room temperature operated at a resolution of $1 \mathrm{~nm}$ between $250 \mathrm{~nm}$ and $800 \mathrm{~nm}$.

\subsubsection{Characterization of silver nanoparticles - Atomic absorption spectroscopy}

AAS was used to analyze the varying concentration of $\mathrm{Ag}^{+}$ions in the solution over a period of time. The conversion of $\mathrm{Ag}^{+}$to $\mathrm{Ag}^{0}$ can be inferred with this measurement. During the course of the reaction at regular intervals, the aliquots of samples were withdrawn and centrifuged at $15000 \mathrm{rpm}$. The supernatant solution was then analyzed by AAS (GBC $932 \mathrm{AA}$ ) to detect the amount of $\mathrm{Ag}^{+}$ions. The rate of decrease in the concentration of the $\mathrm{Ag}^{+}$ions depicts the conversion of $\mathrm{Ag}^{+}$to $\mathrm{Ag}^{0}$.

\subsubsection{Characterization of silver nanoparticles - FTIR analysis}

Fourier transform infrared spectroscopy (FTIR) measurement was carried out to recognize the interaction between the $\mathrm{Ag}$ nanoparticles and the capping agent, from the date extract. For this, the biosynthesized Ag nanoparticle solution was centrifuged at $14000 \mathrm{rpm}$ for $15 \mathrm{~min}$ in order to remove any free biomass residue or compound that is not the capping ligand in the nanoparticles. The $\mathrm{Ag}$ nanoparticle pellet obtained after centrifugation was re-dispersed in water and washed three times with $20 \mathrm{ml}$ of the same water. The samples were dried and grinded and analyzed on a Nicolet IR 200 (Thermo Electron Corp.) model, at a resolution of $2 \mathrm{~cm}^{-1}$. FTIR is taken for the date extract and also for the silver nanoparticles prepared from date extract, to identify the functional groups present in the date extract that are responsible for reduction of silver nanoparticles. 


\subsubsection{Antimicrobial activity of silver nanoparticles by disc diffusion method}

The prepared nutrient-agar was poured onto sterile petri plates and $17 \mathrm{~h}$ growing cultures of gram positive $B$. subtilis \& $S$. aureus and gram negative E. coli were swabbed onto the agar plates. Meanwhile, the sterile discs were impregnated with different concentrations of silver nanoparticles (50, 100 and $150 \mu \mathrm{g} / \mathrm{ml}$ aqueous solution) previously prepared and positive control drug (antibiotic Ciprofloxacin) were placed inverted on the swabbed plat. Empty sterile disc was kept as negative control. The plates were incubated at $37^{\circ} \mathrm{C}$ for $24 \mathrm{~h}$. The antibacterial activity was evaluated by measuring the diameter of the inhibition zone (DIZ) of the tested bacteria (mm). All tests were performed in triplicates (Cruickshank, 1968).

\subsubsection{Antimicrobial activity of prepared edible film reinforced with silver nanoparticles \\ 2.2.8.1. Edible film preparation}

$5 \mathrm{gm}$ of high methoxy pectin were mixed with distilled water $(100 \mathrm{ml})$, polyvinyl alcohol $(1.25 \%$ $\mathrm{w} / \mathrm{v})$ and $2.5 \%$ glycerol $(\mathrm{w} / \mathrm{v})$ at room temperature $\left(25^{\circ} \mathrm{C}\right)$ for $5 \mathrm{~min}$., then the suspension was transferred to a water bath at $90^{\circ} \mathrm{C}$ for $30 \mathrm{~min}$., and agitated by magnetic stirrer $(500 \mathrm{rpm})$, following by cooling at $40^{\circ} \mathrm{C}$. Aqueous solution of different concentration from silver nanoparticles (pellets) previously prepared (50,100 and $150 \mu \mathrm{g} / \mathrm{ml}$ aqueous solution) were added. After the components of the film had been mixed, the films were cast by pipetting $10 \mathrm{ml}$ of the solution into sterile petri plates (VWR) with inner diameters of $10 \mathrm{~cm}$ and allowed to dry overnight $(18 \mathrm{~h})$ in a laminar air flow cabinet under a flow of sterile air at $25^{\circ} \mathrm{C}$. A control film sample was prepared by the same procedure without adding of silver nanoparticles solution.

\subsubsection{Antimicrobial activity of film samples}

Antimicrobial activity of the films were examined for their inhibitory effect on the growth of $E$. coli 0157:H7. Test microorganisms was inoculated in $20 \mathrm{ml}$ of nutrient agar (NA) media and subsequently incubated at $37^{\circ} \mathrm{C}$ for $16 \mathrm{~h}$. The cultured broth was centrifuged at $2000 \mathrm{rpm}$ for $10 \mathrm{~min}$., and the cell pellets were suspended in $100 \mathrm{ml}$ of sterile NA and diluted 10 times with sterile distilled water. $20 \mathrm{ml}$ of diluted broth $\left(10^{6}-10^{7} \mathrm{CFU} / \mathrm{ml}\right)$ was taken into conical flask containing $100 \mathrm{mg}$ of film sample and subsequently incubated at $37^{\circ} \mathrm{C}$ for $16 \mathrm{~h}$ under mild shaking. The cell viability was inoculated in plates of NA. The microorganisms was calculated by counting bacteria colonies on the plates at $0,4,8,12,16$ and $20 \mathrm{~h}$. Antimicrobial tests were performed in triplicate with individually prepared films (CLSI, 2012).

\subsubsection{Patty preparation and microbiological analysis}

A $20 \mathrm{gm}$ of homogeneous ground beef meat patty samples were prepared. The patties were separated into five groups; uncoated, coated with $50 \mu \mathrm{g} / \mathrm{ml}$ silver nanoparticles film, coated with 100 $\mu \mathrm{g} / \mathrm{ml}$ silver nanoparticles film, coated with $150 \mu \mathrm{g} / \mathrm{ml}$ silver nanoparticles film and coated with pure pectin based materials (control film). The beef meat patties were coated by dipping them into the prepared coating solutions for 5 second at room temperature, then drying for 30 second. This dipping procedure was repeated three times, then the patties were dried for $2 \mathrm{~h}$ in a laminar flow hood at $25^{\circ} \mathrm{C}$ and kept in refrigerator for five weeks.

After the end of storage, each packaged sample from each treatment were aseptically opened and a 10-g-portion from the center of the patties was homogenized in sterile maximum recovery diluent (Merck) in a Seward stomacher for $1 \mathrm{~min}$. to make the initial dilution. Appropriate serial dilutions $\left(10^{-1}-10^{-6}\right)$ were spread plated on Plate Count Agar for total viable counts (TVC), Hi Crome agar medium for E. coli 0.157:H7, Baird Parker agar + egg yolk tellurite emulsion for S. aureus, Tryptose Sulfite Cycloserine (T.S.C) agar base for cl. Perfringens and selective agar base medium (PEMBA) for B. cereus (Downes and Ito, 2000).

\section{Results and Discussion}

\subsection{UV-visible spectroscopy analysis}

Solutions with different concentrations of $\mathrm{AgNO}_{3}(1 \mathrm{mM}$, to $4 \mathrm{mM})$ were prepared and $10 \mathrm{ml}$ of date extract added to each solution. As shown in Fig (1), the absorption peaks obtained for these samples are in the range of $420-435 \mathrm{~nm}$, which is prescribed for Ag nanoparticles. Hence, the results obtained 
ensure the existence of Ag nanoparticles in the solutions. Since the surphace plasmon resonance SPR peak centered near $410 \mathrm{~nm}$. A similar pattern was observed by Zarchi, et al., (2011), using an Andrachnea chordifolia ethanol extract as reducing agent.
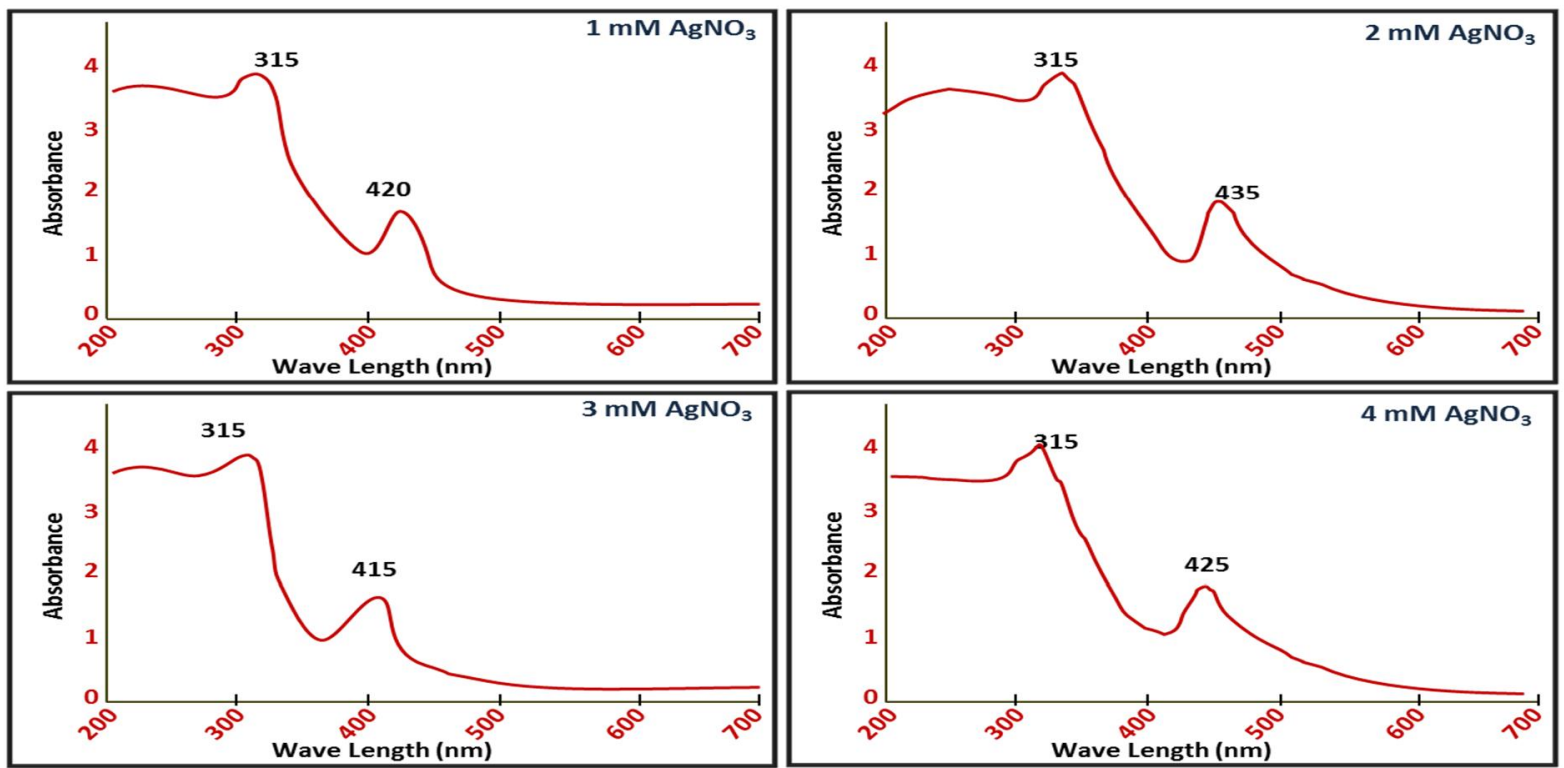

Fig. 1: UV spectrum of $\mathrm{Ag}$ nanoparticles obtained by 1-4 mM AgNO3 and date syrup extract

UV-Vis absorbance of date extract also showed small absorbance about $315 \mathrm{~nm}$ indicating the presence of phenols in the extract. The absorption peaks disappeared during the reaction which indicates the role and involvement of phenols in the reaction (Fig. 2).

The absorption peak is found to be narrow and single peaked shows that the shape of the silver nanoparticles reduced by date extract is found to be spherical and the particles are monodispersed.

Date extract changed the color of $\mathrm{AgNO}_{3}$ solution gradually from transparent to dark brown due to the reduction of $\mathrm{Ag}^{+}$to $\mathrm{Ag}^{0}$ within 26 min. of commencement of the reaction which further remained constant. Thus, silver ions reduction was done by date extract within a short period of time and the stability of biosynthesis silver nanoparticles was improved when the reduction was completely done.

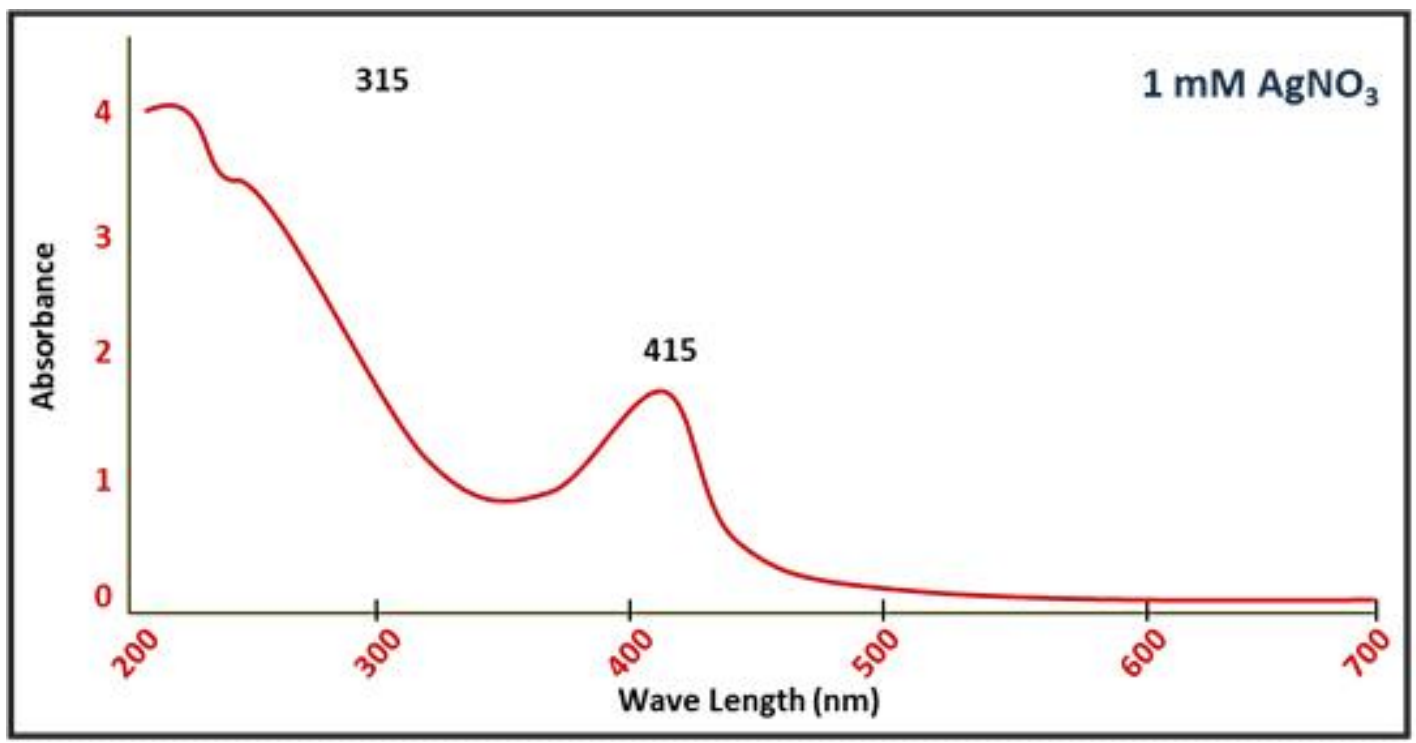

Fig. 2: UV-visible spectra of aqueous solution of $1 \mathrm{mM} \mathrm{AgNO3}$ with the date extract after $12 \mathrm{~min}$. of commencement of the reaction. 


\subsection{Atomic absorption spectroscopy analysis (AAS)}

AAS analysis for the reacting solution done at regular intervals to analyze the varying concentration of $\mathrm{Ag}^{+}$ions in the solution over a period of time $(24 \mathrm{~min})$. The conversion of $\mathrm{Ag}^{+}$to $\mathrm{Ag}^{0}$ can be inferred with this measurement. A standard solution of $6.0 \mathrm{ppm}$ of $\mathrm{AgNO}_{3}$ was prepared and analyzed with $\mathrm{AAS}$ at $0 \mathrm{~min} . \mathrm{Ag}^{+}$ions concentration in the reaction solution after adding date extract, was monitored at regular time intervals (zero, 4, 8, 12, 16, 20 and $24 \mathrm{~min}$.). The results showed decrease in concentration of $\mathrm{Ag}^{+}$ions; 5.6, 4.5, 2.6, 2.4, 1.5, 0.8 and $0.04 \mathrm{ppm}$ respectively, indicating the conversion of $\mathrm{Ag}^{+}$to $\mathrm{Ag}^{0}$ and its rate of $\mathrm{Ag}^{+}$decreasing in the solution (Fig. 3).

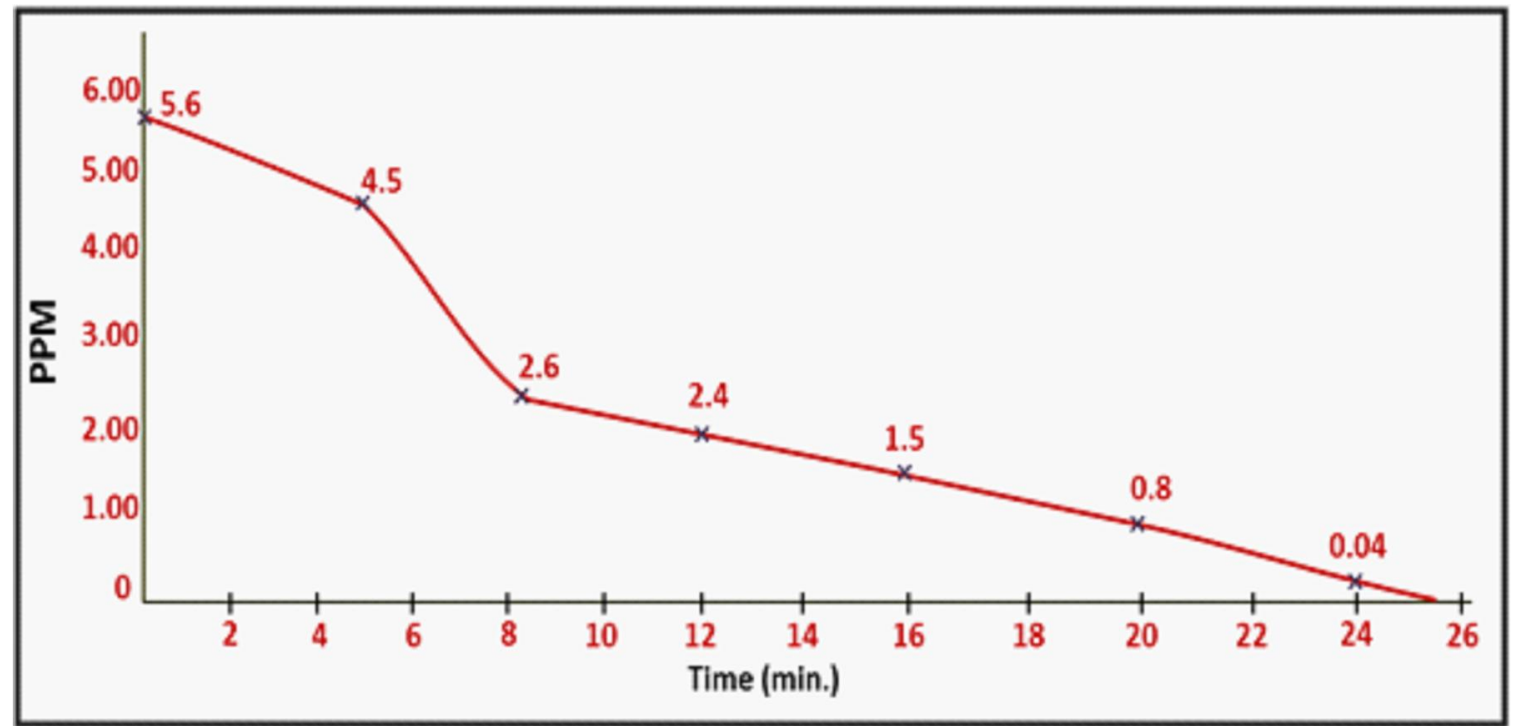

Fig. 3: Atomic absorption spectroscopy graph of $\mathrm{Ag}^{+}$concentration in reaction mixture.

\subsection{FTIR analysis}

Results of FTIR study showed transmittance peaks located at $3315 \mathrm{~cm}^{-1}, 2360 \mathrm{~cm}^{-1}, 1636 \mathrm{~cm}^{-1}$ and $608 \mathrm{~cm}^{-1}$ (Fig. 4). The major peak was assigned at $3315 \mathrm{~cm}^{-1}$ which indicates $\mathrm{OH}$ stretching in alcohols and phenols. The alcohols present in the date extract are caphiol and campherol. The linkage at $2360 \mathrm{~cm}^{-1}$ confirms the presence of the $\mathrm{CH}_{3}$ and $\mathrm{CH}_{2}$ stretching and the peak at $1636 \mathrm{~cm}^{-1}$ confirms the carbonyl stretch $\mathrm{C}=\mathrm{O}$ (Priti et al., 2013). The peaks formed at the $608 \mathrm{~cm}^{-1}$ confirms the $\mathrm{C}-\mathrm{S}$ stretch in the analysis (Jeyashree and Revathi, 2017).

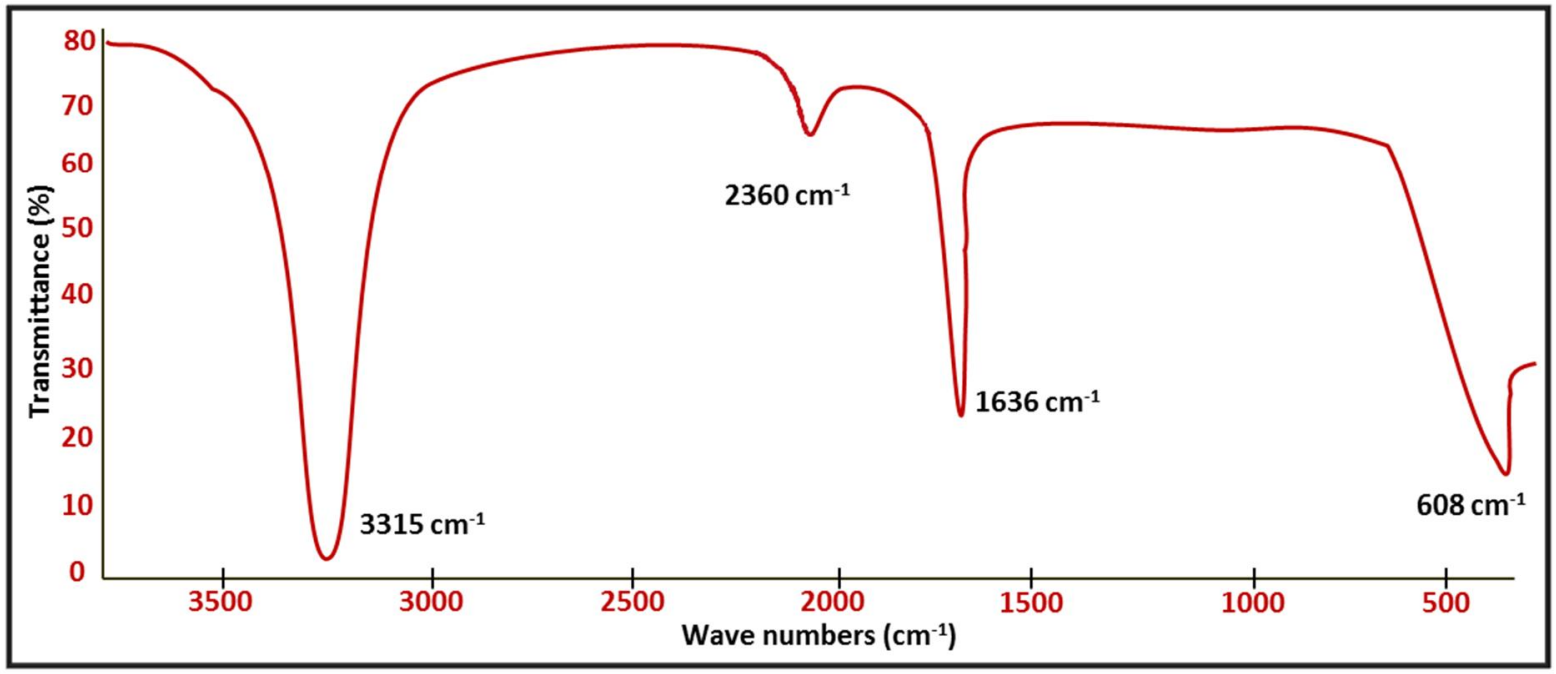

Fig. 4: FTIR spectrum of silver nanoparticle from date extract 
Phenolic compounds belonging to the lignans group have been earlier reported to be capable of chelating with metallic elements to form complexes (Sharma et al., 2014). Thus, it can be concluded that hydroxyl and carboxyl groups present in phenolic compounds of the date extract may inactivate silver ions by chelating and additionally suppressing the superoxide driven reaction, which is believed to be the most important source of reactive oxygen species (Jayashree \& Revathi, 2017). These results confirm the presence of polyphenols and flavones which may act as reducing and stabilizing agents for silver nanoparticles.

\subsection{Antimicrobial activity analysis:}

Antimicrobial activity of biosynthesized silver nanoparticles was analyzed against gram negative $E$. coli and against gram positive $S$. aureus and $B$. subtilis. The inhibition tests were carried out by disc diffusion method. Growth inhibition of bacteria by Ag nanoparticles was compared with standard antibiotic Ciprofloxacin. Inhibition zone diameter $(\mathrm{mm})$ of the different synthesized silver nanoparticles concentrations over the microorganisms is shown in Table (1).

Data shows the inhibition zones diameters for three concentrations from Ag nanoparticles. Increase concentrations gave increase in bacteria inhibition. The gram positive bacteria were most affected compared with gram negative. Inhibition zones of E. coli $9 \mathrm{~mm}$ at concentration $150 \mathrm{ppm}$, while it was $9 \mathrm{~mm}$ at concentration $50 \mathrm{ppm}$ for b. subtilis. At $150 \mathrm{ppm}$, the inhibition zones for all bacteria were 9 to 12 at concentration $150 \mathrm{ppm}$. Thus the silver nanoparticles of date extract significantly inhibits the pathogens and were competent enough with the standard antibiotic indicating stronger antimicrobial activity of biosynthesized silver nanoparticles which may be due to their increased area.

Table 1: Zones of inhibition for concentration of biosynthesized silver nanoparticles against gram negative and gram positive bacteria.

\begin{tabular}{lccc}
\hline \multirow{2}{*}{ Bacteria } & \multicolumn{3}{c}{ Zones of inhibition for AgNPs concentration (mm) } \\
& $\mathbf{5 0} \mathbf{~ p p m}$ & $\mathbf{1 0 0} \mathbf{~ p p m}$ & $\mathbf{1 5 0} \mathbf{~ p p m}$ \\
\hline E. coli & 0 & 0 & 9 \\
S. Aureus & 12 & 16 & 21 \\
B. Subtilis & 9 & 14 & 18 \\
Ciprofloxacin (Antibiotic) & 14 & 19 & 23 \\
\hline
\end{tabular}

Therefore, these silver nanoparticles can be used in low doses of antimicrobial treatment in comparison to standard antimicrobial agents. Also, because of the biological reducing and capping agents, these silver nanoparticles are also environment friendly and non-toxic in comparison to chemically synthesized silver nanoparticles.

\subsection{Effect of edible films with different concentration of $S$. nanoparticles on the growth of different microbial flora}

Results in Table (2) explained the effect of three pectin films incorporated with S. nanoparticles $(50,100$ and $150 \mu \mathrm{g} / \mathrm{ml}$ aqueous solution) after 5 weeks of storage the meat patty samples in refrigerator $\left(4^{\circ} \mathrm{C}\right)$.

It has been found that the numbers of aerobic colonies was decreased with all biolife film tested. The highest decrease in colonies was appeared with $150 \mu \mathrm{g} / \mathrm{ml} \mathrm{S}$. nanoparticles film and the lowest decrease were found in $50 \mu \mathrm{g} / \mathrm{ml} \mathrm{S}$. nanoparticles film. This diminution represent eight-fold the decreasing of the control sample (Table 2). Similarly, all the tested biolife films were able to decrease the number of $S$. aureus. All three films specimens exhibited no any colony count has been found for E. coli $0157: \mathrm{H} 7, \mathrm{Cl}$. perfringens and $B$. cereus after 5 weeks of storage the samples at $4^{\circ} \mathrm{C}$.

It has been concluded that $150 \mu \mathrm{g} / \mathrm{ml}$ film followed by $100 \mu \mathrm{g} / \mathrm{ml}$ film were found to have the best results against all tested microorganisms.

The results were agreement with many studies demonstrated that green silver nanoparticles have a strong antimicrobial activity when incorporated into the packaging edible films. 
Table 2: Effect of edible films incorporated with different concentration of AgNPs on the growth of different microbial flora when used to pack meat patties after 5 weeks storage at $4^{\circ} \mathrm{C}$.

\begin{tabular}{|c|c|c|c|c|c|}
\hline Samples & $\begin{array}{c}\text { Aerobic colony } \\
\text { count }\end{array}$ & $\begin{array}{c}E . \text { coli } \\
0157: H 7 \\
\text { CFU } / \mathbf{g} \times 10\end{array}$ & $\begin{array}{c}\text { S. aureus } \\
\text { CFU } / \mathrm{g} \times 10\end{array}$ & $\begin{array}{c}\text { Cl. Perfringens } \\
\text { CFU } / \mathrm{g} \times 10\end{array}$ & $\begin{array}{c}\text { Bacillus } \\
\text { Cereus } \\
\text { CFU } / \mathbf{g} \times 10\end{array}$ \\
\hline F.C.S & $114 \times 10^{4}$ & 12 & 18 & 6 & $\mathrm{n} / \mathrm{d}$ \\
\hline C.S & $252 \times 10^{4}$ & 25 & 91 & 15 & $\mathrm{n} / \mathrm{d}$ \\
\hline Control & $125 \times 10^{3}$ & 17 & 14 & 6 & $\mathrm{n} / \mathrm{d}$ \\
\hline $\mathbf{A}$ & $57 \times 10^{3}$ & - & 10 & $\mathrm{n} / \mathrm{d}$ & $\mathrm{n} / \mathrm{d}$ \\
\hline B & $34 \times 10^{3}$ & - & 6 & $\mathrm{n} / \mathrm{d}$ & $\mathrm{n} / \mathrm{d}$ \\
\hline $\mathrm{C}$ & $15 \times 10^{3}$ & - & 2 & $\mathrm{n} / \mathrm{d}$ & $\mathrm{n} / \mathrm{d}$ \\
\hline
\end{tabular}

$\begin{array}{lll}* \text { F.C.S } & : & \text { Fresh sample at zone time without film. } \\ \text { * C.S } & : & \text { Uncoated sample after storage at } 4^{\circ} \mathrm{C} \text { for } 5 \text { weeks. } \\ \text { * Control } & : & \text { Zero ppm AgNPs film } \\ \text { * A } & : & 50 \mathrm{ppm} \text { AgNPs film } \\ \text { * B } & : & 100 \mathrm{ppm} \text { AgNPs film } \\ \text { * C } & : & 150 \mathrm{ppm} \text { AgNPs film } \\ \text { * } \mathrm{n} / \mathrm{d} & : & \text { Not detected in } 25 \mathrm{gm} . \\ \text { * } & : & \text { Negative in } 10 \mathrm{gm} . \\ \mathrm{CFU} / \mathrm{g} & : & \text { Colony forming units per gram. }\end{array}$

\section{Conclusion}

In conclusion, the bioreduction of silver ions using date extract as reducing agent has been illustrated. From the present study, it is clear that the silver nanoparticles synthesized by date extract can serve as a suitable reducing agent for biosynthesis of silver nanoparticles within 26 min. of reaction time. UV spectrum, AAS and FTIR results confirmed the formation of silver nanoparticles. The UV spectra peaks for silver nanoparticles range 420 to $435 \mathrm{~nm}$. and were found to be mono-dispersed. From FTIR spectrum, they were found to be stable due to the presence of bioactive compounds such as polyphenols in the extract which act as capping agent and prevent the particle from aggregation. AAS results showed an obvious decrease of $\mathrm{Ag}^{+}$ions and an increase in $\mathrm{Ag}^{0}$ in the solution. This study also showed that biosynthesized silver nanoparticles using date extract have potent antimicrobial activities against $E$. coli (gram negative) and $S$. aureus \& B. subtilis cells (gram positive). Thus, this approach can be applied for rapid cost effective and ecofriendly green synthesis of silver nanoparticles for industrial field without the involvement of toxic chemicals.

Results revealed that there are a significant inhibits to the pathogens and were competent enough with the standard antibiotic.

Finally, the blend of pectin/AgNPs films are expected to be used for the edible film or coating of foods with antimicrobial activity have a potential to be used as food packaging materials for maintaining the safety and extending the shelf life of packaged food.

\section{References}

Aungkana, O., S. Shi, F.W. Long, S. Rungsinee, and W.R. Jong, 2016. Preparation of antimicrobial agar / banana powder blend films, forced with silver nanoparticles. Food Hydro Colloid, 60: $476-485$.

Balaprasad, A., D. Chinmay, A. Absar, and S. Murali, 2005. Biosynthesis of Gold and Silver nanoparticles using Emblico officinalis fruit extract. Colloids Surf Bio-interfaces, 82 (1): 152159.

Bourgou, S., A. Pickette, B. Marzouk, and J. Legault, 2012. Antioxidant, anti-inflammatory, anticancer and antibacterial activities of extracts from Nigella sativa (Black cumin) plant parts. J. Food Biochem., 36 (5): 539 - 546.

Bukar, A., A. Uba, and T. Oyeyi, 2018. Antimicrobial profile of Moringa oleifera lam. Extract against some food-borne microorganisms. Bayero J. of Pure \& App. Sci., 4: 125 - 131. 
CLSI, 2012. Methods for Dilution Antimicrobial Susceptibility Tests for Bacteria. Clinical Laboratory. Standard Inst. M07-Ag, $9^{\text {th }}$ Endn. Wayne.

Cruickshank. R., 1968. Medical microbiology: A guide to diagnosis and control of infection, $11^{\text {th }}$ edn. E \& S livingstone Ltd. Edinburgh and London, 896.

Dinesh. S., S. Karthikeyan, and P. Armngam, 2012. Biosynthesis of silver nanoparticles from Glycyrrhiza glabra root extract. Elixir Optical Mat., 44: 7364 - 7366.

Downes, F. P. and K. Ito, 2001. Compendium of method for the microbiological examination of foods, $4^{\text {th }}$ Ed., APHA, Washington D. C.

Ducan, T.V., 2011. Application of nanotechnology in food packaging and food safety: Barrier Materials, Antimicrobial and sensors. J. Colloid Interface Sci., 36: 1- 24.

Dwiveli, A.D., and K. Gopal, 2010. Biosynthesis of silver and gold nanoparticles using Chenopodium album leaf extract. Colloids Surfaces A: Physico Chem. Eng. Aspac., 369: 27 - 33.

Grazlela, V.L., R.S. Mirella, F.P. Luis, C.G. Marostegan, and G.J. Camila 2017. Physico Chemical stability of beta carotene loaded lipid nanoparticles of cupuacu butter. J. of Food Eng., 192: 93 -102 .

Jeyashree, N.M. and L. Revathi, 2017. Synthesis of NgNPs of Cuminum cyminum seed extract, characterization and antimicrobial activity. Int. J. of Eng. Sci. and Computing, 7(7): 14193 14196.

Keiper, A., 2020. The nanotechnology revolution, New Atlantis J. of Tech. \& Society 2019.

Khalil, M.S., Z.S. Ahmed, and A.S. Rinawawy, 2013. Evaluation of the physicochemical properties and antimicrobial activities of bioactive biodegradable films. J. Biol. Sci., 6: $51-60$.

Krishnaraj, C., E.G. Jagan, S. Rajasekar, P. Selvakumar, P.T. Kalaichelvan, and N. Mohan, 2010. Synthesis of silver nanoparticles using Acalypha indica leaf extract and its antibacterial activity. Colloids Surfaces Biointerfaces, 76: 50 - 56.

Neethirajan and Jayas, D.S., 2011. Nanotechnology for the food and bioprocessing industries. Food Bioprocess Technol., 4: $39-47$.

Prathna, T.C., N. Chandrasekaran, A.M. Raichur, and A. Mukhherjee, 2011. Biomimetic synthesis of silver nanoparticles by Citrus limon Aqueous Extract and Theoretical Prediction of Particle size. Colloids Surf. B. Biointerfaces. 82(1): $152-159$.

Priti, R., P.D. Merina, and K. Sathish, 2013. Green synthesis and characterization of silver nanoparticles from Nigella sativa and its application against UTI causing bacteria. J. of Academia and Ind. Res., 2(1): $45-49$.

Reem, A. A., Jawhara, H., Al-Mashiqri, S.M. Jawaher, I.A. Al-Nadabi, and B. Younis, 2017. Date Palm Tree (Phoenix dactylifera L.): Natural Products, Total Phenolic content and Antioxidant Capacity. Plant Sci., 8: $1-12$.

Sahoo, S.K., S. Parveen, and J.J. Panda, 2019. The present and future of Nanotechnology in human health care. Nanomedicine, 15: 2007.

Sharma, G., A.R. Sharma, M. Kurian, R. Bahavesh, J.S. Nam, and S.S. Lee, 2014. Green synthesis of silver nanoparticle using Myristica fragrans (Nutmeg) seed: Extract and its biological activity. Digest J. of Nanomaterials and biostructures, 9 (1): 325 - 332.

Silambarasan, S. and A. Jayanthi, 2013. Biosynthesis of silver nanoparticles using Pseudomonas fluorescens. Res. J. Biot., 8 (3): $71-75$.

Supraja, S., S.M. Ali, N. Chakravarthy, A. Jaya Prakash Priya, E. Sagadevan, M.K. Kasinathan, S. Sindhu, and P. Anumugam, 2013. Green Synthesis of Silver nanoparticles from Cynodon dactylon leaf extract. Int. J. Chem. Tech., 5(1): $271-277$.

Vigneshwaran, N., N.M. Ashtaputre, P.V. Varadarajan, R.P. Nachane, K.M. Paraliker, and R.H. Balasubramanya, 2017. Biological synthesis of silver nanoparticles using the fungus Aspergillus flavus. Mater Lett., 61: 1413 - 1418.

Zarchi, A.A. K., N. Mokhtari, M. Arfan, T. Rehman, M. Ali, M. Amini, R.F. Majidi, and A.R. Shahverdi, 2011. A sunlight-induced methods for rapid biosynthesis of silver nanoparticles using an Andrachnea chordifolia ethanol extract. Appl. Physics., 103(2): 345 - 353. 